\title{
Root Regeneration in Transplanted Deciduous Nursery Stock
}

\author{
Daniel K. Struve \\ Department of Horticulture, The Ohio State University, Columbus, OH 43210
}

A common observation is that a period of slow growth follows the transplant of deciduous nursery stock. The reduced growth is characterized as transplant shock (Watson, 1986) and is attributed to the drastic reduction of the root system and a resulting increase in the shoot : root ratio (Watson and Sydnor, 1987). Once vigorous growth resumes, the plant is considered to be established or recovered from transplant shock. The time between transplant and resumption of vigorous growth is termed the establishment period. Physiological processes during this period have not been adequately studied and a workable definition of when establishment occurs has not been made.

\section{Root growth capacity or potential}

Root regeneration and the concomitant return to pre-transplant shoot : root ratios are essential for the survival and establishment of transplanted trees (Larson, 1980; Stone et al., 1962; Watson, 1986). Root growth capacity (Burdett, 1987; Sutton, 1980) or potential (Ritchie and Dunlap, 1980) is the measure of the planting stock's capability to regenerate roots in a given period, typically 30 days or less, in a benign environment (Sutton, 1987). Characteristics, such as the number of new roots, roots longer than a given length, total root length, or number of seedlings that have regenerated roots, are used to quantify root growth. This value is termed root growth capacity (RGC) or potential (RGP). The putative significance of RGC is that it can be used to predict field survival and performance. While RGC of deciduous species will be discussed herein, root growth capacity in conifers and its relation to field survival and performance has been reviewed in these proceedings and elsewhere (Burdett, 1987; Ritchie and Dunlap, 1980; Sutton, 1987).

Three components of RGC are number and length of roots, their weighted product, and total root surface area (Sutton, 1987). New growth results from elongation of existing lateral roots and from initiation and elongation of adventitious roots (Stone and Schubert, 1959). Elongation of existing roots occurs whenever soil conditions (soil moisture, temperature, and adequate oxygen) permit. In northern temperate regions, soil conditions conducive to root growth exist in spring and fall, while, in the summer, dry soil and high temperatures are common and inhibit root growth. Adventitious root regeneration occurs primarily in the spring.

Ritchie and Dunlap (1980) summarized development and expression of RGC. At any point, RGC can be significantly decreased by improper growing, storage, or handling practices. For example, dehydrated planting stock can significantly reduce RGC and shoot

Salaries and research support provided by state and federal funds appropriated to the Ohio Agricultural Research and Development Center, The Ohio State Univ. Manuscript number 197-88. vigor (Couts, 1981; Insley, 1980; Insley and Buckley, 1985). Most root regeneration research is conducted with the assumption that experimental material has not been exposed to conditions that contravene root growth potential before administering experimental treatments. This assumption will be used here.

This review will focus on root regeneration and regrowth in bareroot deciduous hardwood stock transplanted when dormant. Emphasis will be given to red oak (Quercus rubra L.) a valuable and widely occurring species in eastern North American forests with highly desirable traits for urban and landscape use. Root regeneration in nondormant stock, typically root-pruned container stock, will not be reviewed, since this was discussed by Geisler and Ferree (1984).

\section{Limitations of root growth potential in hardwood stock}

To date, RGC determinations have not been used to index the growth potential of hardwood planting stock. This determination would have applicability for some bare-root species and for containerized material that would have rapidly regenerating intact roots or where adventitious root regeneration is rapid. However, with coarse-rooted species, such as red oak, which have few intact root tips and where adventitious root regeneration can take as much as 50 days (Struve and Rhodus, 1988), RGC would have limited value for rapidly predicting field survival and growth potential. For the purpose of explanation in this paper, a fibrous-rooted species is defined as one having many first- and second-order lateral roots and a coarse-rooted species as one having few first- and secondorder lateral roots.

Plants have been placed in an easy- to difficult-to-transplant continuum based on transplant survival. Ease of transplanting has been linked with root morphology and the rate of root regeneration. Species with fibrous root systems are easier to transplant than species with coarse root systems (Struve et al., 1983; Struve and Moser, 1984a). As an example, the easy-to-transplant pin oak (Q. palustris L.) had significantly more first-, second-, and third-order laterals than the difficult-to-transplant scarlet oak (Q. coccinea Muench.) (Struve and Moser, 1984a). Futhermore, pin oak regenerated more roots faster than did scarlet oak (Struve and Moser, 1984b). If coarse-rooted species are raised in open-bottomed containers, a more fibrous root system can be developed (Dixon et al., 1981a) and transplant success and regrowth increased (Dixon et al., 1981b).

An intergeneric comparison illustrates the root regeneration characteristics of a relatively easy- (green ash, Fraxinus pennsylvanica Bork.) and difficult- (red oak) to-transplant species. Intact green ash root tips began elongation within 9 days of transplanting and adventitious roots were regenerated within 17 days (Arnold, 1987). For red oak seedlings, adventitous root regeneration occurred within 24 days from pruned lateral roots and from the main root 49 days 
after transplanting (Struve and Rhodus, 1988). Root regeneration is predominantly adventitious in red oak and other coarse-rooted species because there are no intact root tips at the time of transplanting (Larson and Whitmore, 1970a, 1970b). Adventitious root regeneration in green ash was more rapid than in red oak, whether expressed relative to budbreak or on an absolute-time basis; both species broke bud within 7 days of transplanting. The importance of rapid root regeneration for subsequent vigorous shoot growth will be discussed later.

\section{Root morphology and root growth capacity}

There are two reasons why fibrous root systems are important to successful transplant. First, fibrous root systems contain intact root tips at harvest. Intact root tips have the potential for rapid regeneration during most of the year. Root regeneration from elongation of existing roots is the primary component in 30-day or less RGC determinations (Stone and Schubert, 1959). Second, the length and number of first-order lateral roots are important, as these roots form the basic framework for the new root network (Nambiar, 1980). The greater the number of primary roots, the greater the potential root growth capacity.

Root system morphology is a good predictor of transplant success (Kormanik, 1986). Sweetgum (Liquidambar styraciflua L.) survival and regrowth was related to the number of primary (permanent) lateral roots present at planting. Seedlings with six or more permanent lateral roots had survival rates of $74 \%$, whereas seedlings with three or fewer lateral roots had survival rates of $49 \%$. A striking finding was that only $25 \%$ of the seedlings from four half-sib families had six or more lateral roots per seedling and $\approx 50 \%$ of all seedlings had three or fewer roots at planting. It was suggested that seedlings with three or fewer roots should be culled.

Soil fertility does not affect the number of primary lateral roots per seedling in radiata pine (Pinus radiata Don) and sweetgum. Complete fertilizer application increased root dry weight, but had little effect on the number and length of primary lateral roots compared with N- or P-deficient seedlings (Nambiar, 1980; Kormanik, 1986). One reason for the lack of significant differences in root length when there were significant differences in root dry weights is that the tap root can account for up to $50 \%$ of the root system dry weight, but only $3 \%$ to $6 \%$ of the total root length (Nambiar, 1980).

\section{Timing of budbreak and first root regeneration}

The time between budbreak and root regeneration is critical to vigorous shoot growth in transplanted red oak (Johnson et al., 1984). Shoot growth was most vigorous where root regeneration was most rapid, $\approx 17$ days after budbreak in container stock. Shoot vigor decreased as time between budbreak and first root regeneration increased. Johnson et al. (1984) emphasized that the goal of seedling production should be planting stock that consistently regenerates roots concurrently with shoot growth. They concluded that this goal is possible, but not often achieved, in oak planting stock because of conventional production and storage methods and not because of inherent growth patterns.

\section{ESTABLISHMENT}

Both dormant deciduous and coniferous transplants need to regenerate a root system. A major difference is that conifers have photosynthetically functional leaves at planting, whereas deciduous stock does not. The capability to photosynthesize soon after transplant is important as new root growth in sitka spruce (Picea sitchensis Carr.) and Douglas fir [Pseudotsuga menziesii (Mirb.) Franco] appears to be highly dependent on current photosynthate (van den Driesche, 1987). Storage compounds become more important to establishment success as planting site conditions worsen. In deciduous stock, stored energy reserves would seem to be critical to survival and growth following transplanting.

\section{Importance of stored carbohydrate to transplant success}

Spring canopy development requires significant amounts of energy in established white oak (Q. alba L.), (McLaughlin et al.,
1980). Between February (the seasonal peak in total tree energy levels) and canopy development in late April, total tree energy level decreased $57 \%$. Of the $17.7-\mathrm{kg}$ glucose equivalent needed for canopy development (for a $410-\mathrm{kg}$ tree), $13 \mathrm{~kg}$ came from within the canopy. Total tree energy level was restored by late June. White oak has the capability to mobilize significant amounts of stored energy and to replace expended energy rapidly (McLaughlin et al., 1980). The capability of established white oak to rapidly replace energy expended in the spring growth flush is critical to its survival. In transplanted hardwood stock, stored reserves, mostly starch (Farmer, 1975a, 1979; Larson, 1975, 1978; McLauglin et al., 1980) would seem to play an even more important role in root regeneration and canopy development, especially if budbreak precedes root regeneration by an extended period. Photosynthesis would be limited under those conditions.

Surprisingly, root carbohydrate concentration has not been highly correlated with regrowth in hardwood stock. One reason is that significant amounts of starch remain after canopy development and root regeneration. For instance, starch concentrations in transplanted sawtooth and white oak were reduced by no more than half during initial leaf development and root regeneration-53\% to $37 \%$ and $46 \%$ to $23 \%$, respectively (Farmer, 1979). A second reason is that starch concentration is difficult to alter. Defoliating in fall or shading red oak seedlings did not affect root carbohydrate concentrations or end-of-season fresh. weight (Larson, 1975). However, when transplanted the following spring, root and shoot growth of shaded and defoliated plants were decreased relative to unshaded seedlings. Root starch content was not correlated with either root or shoot growth. Defoliation as late as October (with leaf drop occurring in early November) was found to decrease seedling vigor. Also, root-pruning red oak (thus decreasing the amount of stored carbohydrate) decreased spring regrowth, but growth was not proportional to the amount of carbohydrate removed (Larson, 1978). Similarly, root carbohydrate was not correlated with survival, root or shoot growth of pin oak and honeylocust (Gleditsia triacanthos L.) whips (S.B. Magley and J.R. Clark, unpublished data) and Tilia (Witherspoon and Lunis, 1986). In these studies, carbohydrate levels were altered by harvesting at different times during fall and early winter.

These results suggest that something other than fall accumulation of carbohydrates is critical for survival and regrowth; possibly a fall-synthesized hormone. However, exogenous spring applications of GA or cytokinins did not compensate for fall shading or defoliation, nor significantly increase root regeneration (Hartwig and Larson, 1980; Smith and Schwabe, 1980).

\section{AUXIN EFFECTS ON ROOT REGENERATION}

Before discussing auxin effects on root regeneration in oak, shoot growth needs to be described. Red oak shoot growth occurs in three distinct phases (Hanson et al., 1986). Each flush begins with a period of shoot extension (Slin), followed by a period of maximum leaf expansion (Llin) and a period of no observable leaf or stem growth (Lag). Stem and leaf growth in a flush is identified with the appropriate suffix; 1-Lag and 2-lag for first and second flush lag phases, respectively.

Auxin applications, typically indolebutyric acid (IBA), have increased root and shoot growth potential of transplanted stock (Kling, 1984; Struve et al., 1983). The means by which auxin applications promote regrowth is not known.

Root regeneration can be promoted by decreasing the time to first root regeneration, increasing root elongation rate, or increasing numbers of roots regenerated. Auxin applications decrease root elongation rate and increase time to first root regeneration (Struve and Moser, 1984b). For instance, IBA applications of 1000 and $3000 \mathrm{ppm}$ to 23-day-old scarlet oak seedlings delayed first root regeneration by 6 and 15 days, respectively, and decreased root elongation rates by 0.3 and $0.5 \mathrm{~cm} \cdot \mathrm{day}^{-1}$, respectively. Similar results were found with tulip poplar seedlings (Kelly and Moser, 1983) and 3-year-old red oak seedlings (Struve and Rhodus, 1988).

Spring auxin applications have consistently increased the number of roots regenerated in both seedlings and larger-sized (up to $15 \mathrm{~cm}$ 
caliper) stock (Kling, 1984; Lumis, 1982; Prager and Lumis, 1983; Magley and Struve, 1983). The most widely used methods of auxin application are root dips or sprays (Kling, 1984, Struve et al., 1983). One caution with IBA applications is that high concentrations inhibit regrowth (Farmer, 1975b; Kelly and Moser, 1983). Two recently developed auxins, $N$ - phenyl indolyl3-butyramide (NPIBA) and phenyl indole-3-thiolobutyrate (P-ITB), increased the number of roots regenerated in stem cuttings (Haissig, 1979, 1983). When applied to red oak seedlings, the number of roots regenerated was increased 7-fold over untreated seedlings (Struve and Arnold, 1986). Registration of P-ITB (Rootall) is being pursued by GroTech, Rapid City, S.D. (Van Sambeek, personal communication).

The typical growth pattern of dormant-transplanted bare root red oak is for shoot extension (1-Slin) and leaf expansion (1-Lin) to be completed before root regeneration. Depending on type of planting stock, root regeneration was initiated 16 to 33 days after budbreak (Johnson et al., 1984). In another study, bare-root 3-year-old seedlings regenerated adventitious roots from pruned small-diameter lateral roots 24 days after budbreak (Struve and Rhodus, 1988). A second cycle of root regeneration occurred 49 days after budbreak from the basal end of the pruned main root. A second flush of shoot growth (2-Slin through 2-Lag) occurred 56 to 63 days after transplanting. IBA application (1000 and 10,000 ppm IBA) delayed root regeneration from the taproot by 4 to 8 days, compared with untreated seedlings, but increased the number of roots regenerated by four to six roots per seedling. Because budbreak occurred before root regeneration, there were no differences in shoot length, leaf area, or leaf size (1-Lag leaves averaged $15.8 \mathrm{~cm}^{2}$ over all treatments) between IBA-treated and untreated seedlings. This phenomenon of no or small treatment differences being expressed in the first flush has been seen repeatedly in red oak (Struve et al., 1983; unpublished data). IBA treatment differences are expressed in the second flush (2-Lag). In the case of 3-year-old red oak, IBA-treated seedlings had more and larger 2-Lag leaves (10 and six leaves, and average leaf sizes of 59 and $46 \mathrm{~cm}^{2}$, respectively) than untreated seedlings. In general, the more roots regenerated, the greater the number and size of leaves in 2-Lag. In addition, the average leaf size in the second flush was increased, regardless of treatment: 15.8 vs. 59 or $46 \mathrm{~cm}^{2}$, for 1-Lag, 2-Lag, IBA-treated and untreated, respectively.

\section{Relative growth rates of transplanted red oak}

It would be reasonable to expect a lower relative growth rate (RGR) during the period 1-Sin to 1-Lag (between budbreak and first root regeneration) than for the period between root regeneration and fall defoliation: 1-Lag or 1-Lag through 2-Lag if a second flush has occurred. Dormant 1-year-old red oak seedlings were treated with $20 \mathrm{mM}$ IBA or remained not treated on 15 May and immediately transplanted to containers to test this hypothesis and the effect of IBA application on RGR. Seedlings were well-fertilized and watered during the experiment. One-half of the seedlings in each treatment were hatvested on 12 June, after leaf expansion of the first flush (beginning of 1-Lag) was completed and root regeneration had just begun. A second harvest was made on 15 Sept. Dry weight of untreated seedlings increased from 4.4 to $6.2 \mathrm{~g}$ during the May-toJune period; dry weight of IBA-treated seedlings increased to $6.1 \mathrm{~g}$. By September, untreated seedlings had more than doubled the initial dry weight $(9.1 \mathrm{~g})$, whereas IBA-treated seedlings had almost tripled (13 g).

During the May-to-June period, RGR was $882 \mathrm{mg} \cdot \mathrm{g}^{-1} \cdot \mathrm{week}^{-1}$ and $854 \mathrm{mg} \cdot \mathrm{g}^{-1} \cdot$ week $^{-1}$ for untreated and treated seedlings, respectively. The June-to-September RGRs were 30 and 55 $\mathrm{mg} \cdot \mathrm{g}^{-1} \cdot$ week $^{-1}$ and the season-long (May to September) RGRs were 43 to $62 \mathrm{mg} \cdot \mathrm{g}^{-1} \cdot$ week $^{-1}$ for untreated and treated seedlings, respectively. For comparison, the maximum season-long RGR of untransplanted red oak seedlings was $259 \mathrm{mg} \cdot \mathrm{g}^{-1} \cdot \mathrm{week}^{-1}$ (Farmer, $1975 \mathrm{~b}$ ). Transplanting greatly reduced the season-long RGR (by $600 \%$ and $400 \%$ for untreated and treated seedlings, respectively), even under conditions of high fertility and optimum soil moisture. However, RGR between May and June, when root regeneration had just begun, was 3.5 times the total season RGR of untransplanted seedlings. Transplanted red oak have the capacity for high RGR, and, by inference, high net assimilation rates and/or leaf area ratios when roots are not present.

Relative growth rate is the product of NAR (dry weight increase per unit leaf area per unit time) and leaf area ratio $\left(\mathrm{cm}^{2}\right.$ of leaf area per unit plant dry weight). Relative growth rate depends on both the amount of foliage displayed and the rate of net $\mathrm{CO}_{2}$ assimilation. An increase in RGR can result from increased surface area, increased rates of assimilation per unit leaf area, or a combination of both. Increased surface area most likely would result from a second flush of growth and be driven by increased assimilation rates resulting from rapid root regeneration. Leaf area and net assimilation rate of the first flush are important to initial plant growth as the four to six first-flush leaves are the major contributors to total shoot $\mathrm{CO}_{2}$ exchange rate through 2-Lag (Hanson et al., 1988b). Even during the 1-Slin phase, red oak leaves have positive net assimilation rates (Hanson et al., 1988a).

In the case of the 1-year-old IBA-treated red oak seedlings, the higher June-to-September and, consequently, the higher season-long RGR can be attributed to increased leaf surface area. More IBAtreated seedlings produced a second flush of growth; final leaf surface areas per seedling were 315 and $229 \mathrm{~cm}^{2}$ for IBA-treated and untreated seedlings, respectively. There were no significant differences in NAR and LAR calculated from seedling dry weights and leaf areas (D.K.S., unpublished data). Preliminary experiments that measured leaf gas exchange of IBA-treated and untreated red oak seedlings showed similar trends (D.K.S., unpublished data). The cause(s) of high RGR during the first month are unknown and warrant additional research.

If red oak seedlings are transplanted in January and placed in a heated greenhouse under extended photoperiods of high-intensity light, the sequence of budbreak preceding root regeneration seen in earlier studies can be reversed and the higher RGR of IBA-treated seedlings negated (D.K.S., unpublished data). Under January conditions, transplanted untreated seedlings had significantly higher RGR than IBA-treated seedlings (49 vs. $37 \mathrm{mg} \cdot \mathrm{g}^{-1} \cdot$ week $^{-1}$, respectively). Two factors contribute to the higher RGR of untreated seedlings. First, untreated seedlings displayed more leaf area (529 vs. $287 \mathrm{~cm}^{2}$ ) and, second, budbreak occurred 11 days after first root regeneration, whereas IBA-treated seedlings broke bud 2 days before first root regeneration. Budbreak occurred 49 and 41 days after transplanting for untreated and IBA-treated seedlings, respectively. The differences in timing between budbreak and root regeneration are reflected in average leaf size (70.5 vs. $38.3 \mathrm{~cm}^{2}$, respectively) for untreated and IBA-treated seedlings. There was no difference in the number of leaves per seedling (D.K.S., unpublished data).

The reversal in timing between budbreak and root regeneration in the red oak study of January is similar to timing between adventitious root regeneration and budbreak in Fraser fir [Abries fraseri (Parsh.) Poir.] stem cuttings (Miller et al., 1982). The number of hours needed to stimulate adventitious root regeneration was less than needed to stimulate budbreak. Budbreak and root regeneration could be separated in time by propagating cuttings that had received sub-optimal chilling exposure with respect to budbreak. Likewise, if dormant nursery stock could be transplanted into warm soil while dormant-season air temperatures are low, it would alter the "normal" pattern of budbreak and adventitious root regeneration, thus increasing transplant success. For most species, a significant increase in root regeneration occurs between 10 and 20C (Struve and Moser, 1985; Larson and Whitmore, 1970b; Stone and Schubert, 1959). No practical means of increasing spring soil temperatures above $20 \mathrm{C}$ has been found to date.

An added complication in field plantings is that by the time soil temperatures warm enough to promote root regeneration [soil temperatures remain <20C in Ohio until mid-June (Larson, 1970b)], low soil moisture levels are inhibitory. For established black walnut (Juglans nigra L.) trees, 96\% of all root growth occurred between soil osmotic potentials of 0 and $-0.5 \mathrm{MPa}$ and $59 \%$ occurred between 0 and $-0.1 \mathrm{MPa}$ (Kuhn et al., 1985). With established white oak trees, no root elongation occurred at soil osmotic potentials below -2.5 MPa (Teskey and Hinckley, 1981). In both studies, 
soil osmotic potentials above $-0.5 \mathrm{MPa}$ were confined to the spring month s.

Red oak adventitious root regeneration is sensitive to moisture stress, being completely inhibited at $0.6 \mathrm{MPa}$ soil osmotic potential and greatly inhibited at $0.4 \mathrm{MP}$, relative to root regeneration at soil osmotic potential maintained at 0.03 and $0.02 \mathrm{MPa}$ (Larson, 1970a; Larson and Witmore, 1970a). As described above, optimum soil temperature and moisture levels for root growth did not occur simultaneously; soil temperature was limiting when soil moisture potential) was not and vice versa (Teskey and Hinckley, 1981). This relationship represents a sobering situation when assessing the likelihood of transplanting success. With the combination of adverse planting site conditions and the loss of at least $91 \%$ of the existing root system during field harvest (Watson and Himlick, 1982; Gilman, 1988), it is remarkable that any plant survives transplanting.

\section{SUMMARY}

Root systems of coarse-rooted species regenerate primarily via adventitious means after transplanting, whereas initial root regeneration of fibrous-rooted species is from elongaton of existing roots and secondarily from adventitious regeneration. Fibrous-rooted species transplant more easily than coarse-rooted species because they have rapidly regenerating intact root tips when planted. Also, they tend to regenerate more adventitious roots faster.

Budbreak occurs before root regeneration in dormant-transplanted stock. A contributing factor to this sequence of events is cool spring soils with root regeneration being inhibited below 10C. Transplant shock is minimized by decreasing the time between budbreak and first-froot regeneration.

Auxin (IBA) applications promote root regeneration by increasing the number of roots regenerated. In recurrently flushing species, such as red oak, effects of IBA treatments are not expressed in the first flush because shoot elongation and leaf expansion are completed before root regeneration occurs. IBA treatment effects are, however, expressed in the second growth flush-IBA-treated plants develop more leaf area (through a combination of increased numbers of leaves and increased leaf size) than untreated seedlings.

Relative growth rates for both IBA-treated and untreated seedlings were higher during the period between budbreak and first root regeneration than after root regeneration. IBA-treated seedlings have higher RGR for the period between first root regeneration and the end of the growing season than do untreated seedlings. However, transplanted red oak have significantly lower season-long RGR than do untransplanted seedlings. The cause of high RGR for the period between budbreak and first root regeneration is unknown.

\section{Literature Cited}

Arnold, M.A. 1987. Cupric carbonate modification of Quercus rubra and Fraxinus pennyslvania root systems and implications for production and transplant. MS Thesis, The Ohio State Univ., Columbus.

Burdett, A.N. 1987. Understanding root growth capacity: theoretical considerations in assessing planting stock quality by means of root growth tests. Can. J. For. Res. 17:768-775.

Couts, M.P. 1981. Effects of root or shoot exposure before planting on the water relations, growth and survival of Sitka spruce. Can. J. For. Res. 11:703-709.

Dixon, R.K., G.M. Wright, H.E. Garrett, C.S. Sox, P.S. Johnson, and I.L. Sander. 1981. Container- and nursery-grown black oak seedlings inoculated with Pisolithus tinctorium: Growth and ecotomycorrhizal development during seedling production period. Can J. For. Res. 11:487491.

Dixon, R.K., H.E. Garrett, C.S. Cox, P.S. Johnson, and I.L. Sander. 1981b. Container- and nursery-grown black oak seedlings inoculated with Pisolithus tinctorium: Growth and ectomycorrhizal development following out planting on an Ozark clear-cut. Can. J. For. Res. 11:492-496.

Farmer, R.E. 1975a. Dormancy and root regeneration of northern red oak. Can. J. For. Res. 5:176-185.

Farmer, R.E. 1975b. Growth and assimilation rate of juvenile northern red oak: effects of light and temperature. For. Sci. 21:373-381.

Farmer, R.E. 1979. Dormancy and root growth capacity of white and sawtooth oaks. For. Sci. 25:491-494.

Geisler, D. and D.C. Ferree. 1984. Response of plants to root pruning. Hort. Rev. 6:155-188.
Gilman, E.F. 1988. Tree root spread in relation to branch dripline and harvestable root ball. HortScience 23:351-353.

Haissig, B.E. 1979. Influence of anyl esters of indole-3-acetic and indole3-butyric acids on adventitious root primordium initiation and development. Physiol. Plant. 47:29-33.

Haissig, B.E. 1983. $N$ - phenyl indolyl-3-butyramide and phenyl indole-3thiolobutyrate enhance adventitious root primordium development. Physiol. Plant. 7:435-440.

Hanson, P.J., J.G. Isebrands, R.E. Dickson, and R.K. Dixon. 1986. A morphological index of Quercus seedling ontogeny for use in studies of physiology and growth. Tree Physiol. 2:273-281.

Hanson, P.J., J.G. Isebrands, R.E. Dickson, and R.K. Dixon. 1988a. Ontogenetic patterns of $\mathrm{CO}_{2}$ exchange of Quercus rubra L. leaves during three flushes of shoot growth: I. Median flush leaves. For. Sci. 34:5568.

Hanson, P.J., J.G. Isebrands, R.E. Dickson, and R.K. Dixon. 1988b. Ontogenetic patterns of $\mathrm{CO}_{2}$ exchange of Quercus rubra L. leaves during three flushes of shoot growth: II. Insertion gradients of leaf photosynthesis. For. Sci. 34:69-76.

Hartwig, R.C. and M.M. Larson. 1980. Hormone root-soak can increase initial growth of planted hardward stock. Tree Planters' Notes 31(1):2933

Insley, H. 1980. Wasting trees? The effects of handling and post planting maintenance on the survival and growth of amenity trees. Arboricult. J. 4:65-73.

Insley, H. and G.P. Buckley. 1985. The influence of desiccation and root pruning on the survival and growth of broadleaved seedlings. J. Hort. Sci. 60:377-387

Johnson, P.S., S.L. Novinger, and W.G. Mares. 1984. Root, shoot, and leaf area growth potentials of northern red oak planting stock. For. Sci. 30:1017-1026.

Kelly, R.J. and B.C. Moser. 1983. Root regeneration of Liriodendron tulipifera in response to auxin, stem pruning and environmental conditions. J. Amer. Soc. Hort. Sci. 108:1085-1090.

Kling, G.J. 1984. Root regeneration techniques. Proc. Intl. Plant Prop. Soc. 34:618-627.

Kormanik, P.P. 1986. Lateral root morphology as an expression of sweetgum seedling quality. For. Sci. 32:595-604.

Kuhn, M.R., H.E. Garrett, R.O. Teskey, and T.M. Hinckley. 1985. Root growth of black walnut trees related to soil temperature, soil water potential and leaf water potential. For. Sci. 31:617-629.

Larson, M.M. and T.W. Whitmore. 1970a. Moisture stress affects root regeneration and early growth of red oak seedlings. For. Sci. 16:495498.

Larson, M.M. and T.W. Whitmore. 1970b. Root regeneration and early growth of red oak seedlings: Influence of soil temperature. For. Sci. 16:442-446.

Larson, M.M. 1975. Pruning northern red oak nursery seedlings: Effects on root regeneration and early growth. Can. J. For. Res. 5:381-386.

Larson, M.M. 1978. Effects of late-season defoliation and dark periods on initial growth of planted northern red oak seedlings. Can. J. For. Res. 8:67-72.

Larson, M.M. 1980. Effects of atmospheric humidity and general soil water stress on initial growth of planted- northern red oak seedlings. Can. J. For. Res. 10:549-554.

Lumis, G.P. 1982. Stimulating root regeneration of landscape-size red oak with auxin root sprays. J. Arboricult. 8:325-326.

Magley, S.B. and D.K. Struve. 1983. Effects of three transplants methods on survival, growth and root regeneration of caliper pin oaks. J. Environ. Hort. 1:59-62

McLaughlin, S.B., R.K. McConathy, R.L. Barnes, and W.T. Edwards. 1980. Seasonal changes in energy allocation by white oak (Quercus alba). Can. J. For. Res. 10:379-388.

Miller, N.F., T.M. Hinseley, and F.A. Blazich. 1982. Rooting of Fraser fir cuttings: effects of postseverance chilling and photoperiod during rooting. Can. J. For. Res. 12:607-611.

Nambiar, E.K.S. 1980. Root configuration and root regeneration in Punis radiata seedlings. New Zealand J. For. Res. 10:249-263.

Prager, C.M. and G.P. Lumis. 1983. IBA and some IBA-synergist increases of root regeneration of landscape-size and seedling trees. J. Arboricult. 9:117-123.

Ritchie, G.A. and J.R. Dunlap. 1980. Root growth potential: Its development and expression in forest tree seedlings. New Zealand J. For. Sci. 10:218-248.

Smith, D.J. and W.W. Schwabe. 1980. Cytokinin activity in oak (Quercus robur) with particular reference to transplanting. Physiol. Plant. 48:2732.

Stone, E.C. and G.H. Schubert. 1959. Root regeneration by Ponderosa Pine seedlings lifted at different times of the year. For. Sci. 5:322-332.

Stone, E.C., J.L. Jenkinson, and S.L. Krugman. 1962. Root regenerating 
potential of Douglas-fir seedlings lifted at different times of the year. For. Sci. 8:288-297.

Struve, D.K., R.D. Kelly, and B.C. Moser. 1983. Promotion of root regeneration of difficult-to-transplant species. Proc. Intl. Plant Prop. Soc. 53:433-439.

Struve, D.K. and B.C. Moser. 1984a. Root system and root regeneration characteristics of pin and scarlet oak. HortScience 19:123-125.

Struve, D.K. and B.C. Moser. 1984b. Auxin effects on root regeneration of scarlet oak seedlings. J. Amer. Soc. Hort. Sci. 109:91-95.

Struve, D.K. and B.C. Moser. 1985. Soil temperature effects on root regeneration of scarlet oak seedlings. OARDC Res. Circ. 284:12-14.

Struve, D.K. and M.A. Arnold. 1986. Aryl esters of indoleutyvic acid increase root regeneration in 3-0 red oak seedlings. Can. J. For. Res. 16:673-675.

Struve, D.K. and W.T. Rhodus. 1988. Phenyl indole-3-thiobutyrate increases growth of transplanted 1-0 red oak. Can. J. For. Res. 18:131134.

Sutton, R.F. 1980. Planting stock quality, root growth capacity and field performance of three boreal conifers. New Zealand J. For. Res. 10:5471.

Sutton, R.F. 1987. Root growth capacity and field performance of Jack pine and black spruce in boreal stand establishment in Ontario. Can. J. For. Res. 17:794-804.

Teskey, R.O. and T.M. Hinckley. 1981. Influence of temperature and water potential on root growth of white oak. Physiol. Plant. 52:363-369.

van den Driesche, R. 1987. Importance of current photosynthate to new root growth in planted conifer seedlings. Can. J. For. Res. 17:776-782.

Watson, G.W. and E.B. Himelick. 1982. Root distribution of nursery trees and its relationship to transplanting success. J. Arboricult. 8:225-229.

Watson, G.W. 1986. Cultural practices influence root development for better transplant success. J. Environ. Hort. 4:32-34.

Watson, G.W. and T.D. Sydnor. 1987. The effect of root pruning on the root system of nursery trees. J. Arboricult. 13:126-130.

Witherspoon, W.R. and G.P. Lumis. 1986. Root regeneration, starch content and root promoting activity in Tilia cordata cultivars at three different digging-planting times. J. Environ. Hort. 4(3):76-79. 